\title{
entre cercas, brincadeiras e feitiços: os conflitos e as apropriações do território por crianças e jovens quilombolas
}

\author{
beatriz corsino perez ${ }^{1}$ \\ universidade federal fluminense, brasil \\ orcid id: https:// orcid.org/0000-0002-8484-5240
}

\begin{abstract}
resumo
o Brasil passou por um longo processo de colonização que ainda deixa marcas violentas nas formas de se relacionar com os povos quilombolas, produzindo a desvalorização de seus conhecimentos e culturas. As vidas de crianças e jovens quilombolas ficaram invisibilizadas diante de um saber científico que usou referências de autores europeus e as classes médias urbanas como modelo. Neste texto, apresentamos os resultados de uma pesquisa-intervenção realizada entre 2017 e 2019, com cerca de trinta crianças e jovens moradores da comunidade quilombola de Cafuringa, em Campos dos Goytacazes - RJ. Buscamos compreender como as experiências de infância e juventude se constituem a partir das relações que crianças e jovens estabelecem com o território, seus usos e apropriações, e os modos de subjetivação diante dos conflitos vivenciados na comunidade. As crianças se apropriam do território através das brincadeiras coletivas realizadas ao ar livre, em que exploram os espaços, interagem com a terra, bichos, plantas e árvores. Para elas, estes elementos podem ser "enfeitiçados", "assombrados" e guardar algo de "sagrado" e, ao mesmo tempo em que fascinam, também geram medo. Essas formas de se relacionar com o território entram em conflito com a "fazenda" e o haras, que fazem fronteira com o quilombo, que consideram a terra como um negócio, os animais e as plantas como mercadorias. Os estranhamentos de crianças e jovens diante da cerca elétrica colocada pelo haras, simbolizando o uso privado da terra, as desigualdades sociais e as discriminações raciais vividas em seus cotidianos nos fazem questionar sobre o projeto de civilização construído na modernidade.
\end{abstract}

palavras-chave: infância, comunidade quilombola, território.

\section{between fences, games and spells: conflicts and appropriations of the territory by children and young quilombolas}

\begin{abstract}
brazil has gone through a long process of colonization that still leaves violent marks in the ways of relating to quilombola communities, producing the devaluation of their cultures and knowledge. Through colonization, the lives of quilombola children and young people have become invisible in the face of scientific knowledge that uses European authors as a reference and the urban middle classes as a model. In this text, we present the results of an interventional research carried out between 2017 and 2019, with about 30 children and young people living in a quilombola community in Cafuringa, in Campos dos Goytacazes-RJ. We seek to understand how the experiences of childhood and youth are constituted from the relationships that children and young people establish with the territory, their uses and appropriations, and the modes of subjectification in the face of conflicts experienced in the community. Children take ownership of the territory through collective games held outdoors, in which they explore
\end{abstract}

1 E-mail: biacorsino@gmail.com 
entre cercas, brincadeiras e feitiços: os conflitos e as apropriações do território por crianças e jovens quilombolas

community spaces, and interact with the land, animals, plants and trees. For these children, these spaces can be "bewitched", "haunted", "sacred", and while fascinating, also generate fear. These ways of relating to the territory are in conflict with the agricultural produce and horse breeding farms, which consider the land as a business, and animals and plants as goods. The children's estrangement in encountering of the electric fence placed by the farm, which symbolizes the private use of the land, social inequalities, and the racial discrimination experienced in their daily lives, leads us to question the project of the overall "civilizing" project built into modernity.

keywords: childhood, quilombola community, territory

\section{entre vallas, juegos y hechizos: conflictos y apropiaciones del territorio por parte de niños y jóvenes quilombolas}

\section{resumen}

Brasil ha atravesado un largo proceso de colonización que todavía deja huellas violentas en las formas de relacionarse con las comunidades quilombolas, produciendo la devaluación de sus culturas y conocimientos. Las vidas de niños y jóvenes quilombolas se volvieron invisibles frente al conocimiento científico que utilizaba a los autores europeos como referencia y a las clases medias urbanas como modelo. En este texto, presentamos los resultados de una investigación de intervención realizada entre 2017 y 2019, con aproximadamente 30 niños y jóvenes que viven en Cafuringa, una comunidad quilombola, en Campos dos Goytacazes-RJ. Buscamos comprender cómo las experiencias de la infancia y la juventud se constituyen a partir de las relaciones que los niños y jóvenes establecen con el territorio, sus usos y apropiaciones, y los modos de subjetivación frente a los conflictos experimentados en la comunidad. Los niños toman posesión del territorio a través de juegos colectivos al aire libre, en los que exploran espacios comunitarios, interactúan con la tierra, los animales, las plantas y los árboles. Para ellos, estos pueden ser "embrujados", mantener algo "sagrado", mientras que fascinante también genera miedo. Estas formas de relacionarse con el territorio entran en conflicto con la granja y criadero de caballos, que consideran la tierra como un negocio, los animales y las plantas como bienes. La extrañeza de los niños frente a la cerca eléctrica colocada por criadero de caballos, que simboliza el uso privado de la tierra, las desigualdades sociales y la discriminación racial experimentada en su vida cotidiana, nos hace cuestionar el proyecto de civilización construido en la modernidad.

palavras clave: niños, comunidades quilombolas, territorio 
entre cercas, brincadeiras e feitiços: os conflitos e as apropriações do território por crianças e jovens quilombolas

\section{1 introdução}

A modernidade concentrou suas expectativas na vida urbana, relacionando a cidade à noção de progresso e desenvolvimento, e o campo ao lugar rude e incivilizado. O saber científico considerou a vida do homem urbano como modelo a ser seguido, o que gerou a desvalorização da vida rural e a desautorização dos saberes ali produzidos por considerá-los "atrasados" ou "primitivos". A crença na razão como instrumento de controle sobre a natureza e os problemas humanos orientou, ao longo do século $X X$, a psicologia do desenvolvimento a produzir conhecimentos sobre o curso da vida humana, de forma a torná-lo previsível e a construir normas e padrões a serem seguidos (Castro, 2001; Burman, 2008). A infância passou a ser compreendida como etapa de vida, amparada no desenvolvimento biológico, que deveria ser superada na vida adulta. No entanto, esse conhecimento que pretendia ser universal, tendo como modelo a criança branca, burguesa, europeia e urbana, passou a ser criticado já que se configurava como uma forma específica de ver a infância, que invisibiliza e silencia os processos de subjetivação de crianças e jovens de diferentes culturas.

Falar de infância e juventude hoje implica considerar estes conceitos como construções sócio-históricas. Ao invés da produção de saberes universais sobre crianças e jovens abstratos, vem sendo produzidos saberes localizados e interdisciplinares, que dizem respeito às crianças e aos jovens do tempo presente, em seus territórios (Castro, 2001). Articular o conceito de infância e juventude às categorias analíticas de raça, gênero, classe social, território passa a ser relevante como uma forma de compreender as experiências dos sujeitos em suas singularidades e diferenças. Envolve também a politização das questões geracionais (Alanen, 2001; Qvortrup, 2011) e a tentativa de entender como as diferenças entre adultos, crianças e jovens são construídas e ganham relevância nos diferentes contextos. Crianças e jovens se apropriam criativamente do mundo adulto para que possam participar e agir diante das situações que lhes afetam. Ou como afirma Cohn (2013, p. 239) acerca da pesquisa em comunidades 
entre cercas, brincadeiras e feitiços: os conflitos e as apropriações do território por crianças e jovens quilombolas

indígenas: "uma infância gerenciada também pelas crianças, que em suas práticas definem sua própria condição infantil".

De acordo com essa perspectiva, o presente artigo parte de uma pesquisaintervenção realizada entre 2017 e 2019, com cerca de trinta crianças e jovens moradores de uma comunidade quilombola, localizada em Campos dos Goytacazes, no norte fluminense. Historicamente, o município se desenvolveu pelo monocultivo da cana-de-açúcar e pelo uso da mão de obra escrava. O latifúndio e o coronelismo dominaram o modelo de desenvolvimento econômico e de governança no município. Embora nas últimas décadas tenha ocorrido a decadência de muitas usinas de etanol, ainda hoje, o corte da cana-de-açúcar é uma importante atividade econômica para os trabalhadores rurais, que são na sua maioria negros. Campos dos Goytacazes também tem o maior número de quilombos do estado do Rio de Janeiro, no entanto, de acordo com a Fundação Cultural Palmares ${ }^{2}$, apenas sete comunidades possuem a certificação. Cafuringa é uma das comunidades remanescentes de quilombos que ainda não tem a certificação e não consta nos registros oficiais do município.

O termo "remanescentes de quilombos" está presente na Constituição Federal de 1988, que afirma o direito possessório às comunidades das terras ocupadas e herdadas por seus antepassados, reconhecendo-as como patrimônio cultural da nação. O termo "remanescente" dá abertura para o entendimento de que a legislação apenas beneficiaria alguns sítios históricos que abrigaram pessoas fugitivas da escravidão, tendo o Quilombo dos Palmares, em Alagoas, como principal referência. Entretanto, atualmente, centenas de comunidades negras rurais espalhadas por todo o país reivindicam o reconhecimento da identidade quilombola (Arruti, 2002). O Decreto $n^{\circ} 4.887$ (Brasil, 2003) trouxe uma nova definição capaz de abarcar comunidades com diferentes características ao considerar "os grupos étnico-raciais, segundo critérios de autoatribuição, com trajetória histórica própria, dotados de relações territoriais específicas, com presunção de ancestralidade negra relacionada com a resistência à opressão histórica sofrida".

2 De acordo com a página oficial da Fundação na internet:

http:/ / www.palmares.gov.br/?page_id=37551 Acesso em 26 de janeiro de 2020. 
Muitas comunidades negras rurais desejam ser reconhecidas como quilombolas para garantirem o uso coletivo da terra e resistirem aos conflitos que enfrentam com grileiros e latifundiários. Estes criam diferentes estratégias para ampliar suas áreas de exploração, desconsiderando os usos e significados que a terra possui para as comunidades tradicionais. Os povos quilombolas estabelecem relações específicas com o território, cujo sentido se relaciona a ciclos de trabalho, conhecimentos, identidades, memórias históricas e culturais. Segundo Santos (2008, p. 96), “o território é o chão e mais a população, isto é, uma identidade, o fato e o sentimento de pertencer àquilo que nos pertence. $\mathrm{O}$ território é a base do trabalho, da residência, das trocas materiais e espirituais e da vida sobre os quais ele influi". Pressupõe, portanto, o espaço e as suas formas de apropriação. A partir disso, nos perguntamos: quais os sentidos que as crianças de Cafuringa atribuem ao seu território? Há alguma especificidade na maneira como se relacionam com a terra, as plantas e os animais? Como compreendem os limites da sua comunidade? Estas são algumas questões que iremos desenvolver ao longo desse artigo.

Em Cafuringa, vivem aproximadamente vinte e cinco famílias, suas ruas não possuem pavimentação, as casas não têm coleta de lixo, nem saneamento básico e uma das maiores dificuldades é o acesso à água potável. Os moradores também sofrem os impactos da instalação de um haras que, desde 2006, ocupou as terras usadas pela comunidade coletivamente e impediu o acesso da população à estrada principal. Esta questão nos remete a afirmação de Acselrad (2004, p. 26): "conflitos ambientais envolvem grupos sociais com modos diferenciados de apropriação, uso e significação do território". Para o autor, conflitos ambientais ocorrem quando um dos grupos tem a continuidade das suas formas sociais de apropriação do meio ameaçadas pelos impactos indesejáveis do exercício da prática de outros grupos sociais, podendo ser pelo solo, água, ar ou sistemas vivos. Há conflito, portanto, porque grupos se recusam a serem submetidos a lugares subordinados e/ou a serem expulsos de seus territórios. Dessa forma, torna-se relevante investigar como o conflito com o haras atravessa a vida de crianças e jovens de Cafuringa, e como impacta suas rotinas, brincadeiras e relações cotidianas. Quais são os seus modos de 
entre cercas, brincadeiras e feitiços: os conflitos e as apropriações do território por crianças e jovens quilombolas

subjetivação, ou seja, suas formas de ver, sentir e agir diante de situações de conflito com o haras?

De acordo com Fanon (2005, p. 61), "para o povo colonizado, o valor mais essencial, porque mais concreto, é primeiro a terra: a terra que deve garantir o pão e, é claro, a dignidade". Além da posse da terra e da reparação dos danos causados pela escravidão, as comunidades quilombolas lutam pela defesa de seus modos de vida: organização social, formas religiosas e de relações com a natureza. Para o autor, "o negro não deve mais ser colocado diante do dilema: branquear ou desaparecer, ele deve tomar consciência de uma nova possibilidade de existir" (Fanon, 2008, p. 95). Os povos quilombolas defendem um mundo diferente ao que está posto, seja em oposição aos grandes latifúndios e a monocultura do campo, seja ao da vida nos grandes centros urbanos. Como Krenak (2019, p. 22) elucida:

Os únicos núcleos que ainda consideram que precisavam ficar agarrados nessa terra são aqueles que ficaram esquecidos pelas bordas do planeta, nas margens dos rios, nas beiras dos oceanos, na África, na Ásia ou na América Latina. São caiçaras, índios, quilombos, aborígenes - a sub-humanidade.

Embora nas últimas décadas os povos quilombolas tenham ganhado maior visibilidade, ainda são poucos os estudos que se dedicam a compreender os processos de subjetivação de crianças e jovens e como se posicionam frente à opressão, ao racismo, à luta pelo território e à defesa de seus modos de vida. Nas pesquisas com esses grupos sociais é preciso tomar cuidado para não utilizar enquadramentos conceituais que neles não cabem, uma vez que estão implicados em outros modos de organizar e gerir a vida social, diferente de crianças e jovens brancos das classes médias urbanas.

Assim, neste artigo, buscamos compreender as relações que crianças e jovens de Cafuringa estabelecem com o território, seus usos e apropriações, e os modos de subjetivação diante dos conflitos ambientais vivenciados na comunidade. Elaboramos uma pesquisa-intervenção com uso de diferentes práticas com o intuito de promover um espaço de escuta e de compartilhamento dos pontos de vista dos participantes acerca de suas realidades. A seguir, apresentamos detalhadamente os procedimentos realizados na investigação do campo empírico. 


\section{2 os desafios do trabalho de campo e o uso de metodologias participativas}

Iniciamos o trabalho na comunidade negra rural de Cafuringa, a partir do contato com a Comissão Pastoral da Terra (CPT). O projeto de pesquisaintervenção "Memória e participação social com crianças e jovens quilombolas" envolveu, quinzenalmente, cerca de trinta crianças e jovens, com idades entre 2 e 24 anos, entre os anos de 2017 e 2019. Utilizamos diferentes metodologias, tais como: caminhadas pela comunidade, brincadeiras, conversas informais, entrevistas semiestruturadas e oficinas em grupo.

$\mathrm{Na}$ pesquisa-intervenção, privilegiamos a interação entre a equipe de pesquisa - composta pela pesquisadora e por estudantes de iniciação científica do curso de Psicologia - e os participantes. Consideramos crianças e jovens como agentes capazes de participar da construção dos encontros e parceiros na produção do conhecimento. Durante o trabalho de campo, há uma troca entre os participantes que são afetados (Favret-Saada, 2005), fazendo com que, simultaneamente, a equipe de pesquisa modifique o contexto no qual ela está inserida e também seja modificada por ele. Nesse sentido, na pesquisaintervenção não há a tentativa de manter a neutralidade do/a pesquisador/a ou garantir um objetivismo cientificista. Faz parte do trabalho a equipe de pesquisa repensar a sua própria história, a sua implicação, os pressupostos da investigação, os caminhos que haviam sido tomados para direcionar as intervenções, que são construídas a partir da análise das demandas e das relações estabelecidas com crianças e jovens em seus territórios.

A ampla faixa etária envolvida no projeto se deu, pois na comunidade há uma convivência grande entre crianças e jovens, que muitas vezes compartilham os mesmos espaços e brincadeiras. Em Cafuringa, as meninas mais velhas cuidam das crianças mais novas enquanto seus familiares estão trabalhando ou se dedicando às atividades domésticas. Nesse sentido, delimitar uma faixa etária para participar do projeto poderia dificultar nossa inserção na comunidade e acabar por reproduzir um modelo escolar que não dialoga com a realidade local.

Foi um desafio para a pesquisa formular propostas de atividades que pudessem despertar o interesse de todos os envolvidos. Em diversos momentos, crianças e jovens assumiram papéis diferentes nas oficinas. As mais velhas 
entre cercas, brincadeiras e feitiços: os conflitos e as apropriações do território por crianças e jovens quilombolas

acabavam nos auxiliando, distribuíam os materiais, ajudavam as crianças pequenas na realização das tarefas ou pediam para que elas fizessem silêncio, evitando brigas e conflitos. Notamos que as crianças pequenas obedeciam e reconheciam a autoridade das jovens mulheres. Em outras horas, todos brincavam e cantavam juntos, compartilhavam histórias e segredos sobre a comunidade. Muitas vezes, as jovens se surpreenderam com a fala de uma criança pequena, de três ou quatro anos, o que gerava risos e também a compreensão de que mesmo os pequenos possuíam opiniões ou algo relevante para ser dito.

Outro desafio enfrentado na pesquisa foi a falta de um espaço para a realização das atividades, uma vez que não consta no território nenhum serviço público ou centro comunitário. Com isso, as atividades foram feitas na varanda da casa de uma liderança e em espaços ao ar livre, indicados pelas crianças. Se por um lado, não ter um espaço fechado impossibilitava a nossa presença nos dias de chuva, por outro, nos permitiu conhecer diferentes lugares e pessoas, e incluir a participação das crianças na escolha do local onde a atividade se desenvolveria. Houve, nesse movimento, um reconhecimento dos saberes das crianças sobre os espaços da comunidade e uma inversão dos lugares geralmente ocupados por adultos e crianças na nossa sociedade. As crianças que guiaram a equipe de pesquisa para uma sombra de árvore, onde colocávamos os panos no chão e iniciávamos os trabalhos do dia.

Nas oficinas em grupo, utilizamos como disparadores histórias e poemas que dialogavam com as temáticas trabalhadas, dando preferência para os que tinham personagens negros, quilombolas ou camponeses. Esta foi uma forma de promover a identificação das crianças e jovens com os personagens e de favorecer o sentimento de representatividade e pertencimento nos materiais utilizados na pesquisa. Fizemos jogos, músicas, desenhos, colagens, dramatizações para fomentar discussões e criar espaços onde os participantes podiam expressar suas opiniões de diferentes maneiras e também ser escutados. Uma das atividades que realizamos foi a produção de um mapa afetivo com o objetivo de conhecer como crianças e jovens representam a sua comunidade, as apropriações e os usos que 
fazem do espaço, os significados produzidos e as maneiras como questionam e interpretam a realidade.

Entregamos também cadernos confeccionados pela equipe de pesquisa, com o propósito de incentivá-los a serem os pesquisadores da sua própria realidade, registrando os acontecimentos importantes, por meio de desenhos e textos. No início de alguns encontros, crianças e jovens compartilharam com a equipe de pesquisa suas produções nos cadernos, iniciando conversas sobre temas que estavam perpassando suas vidas naquele momento. Notamos o interesse, principalmente, das meninas pela escrita de poemas e utilização de rimas, que fazem parte de uma tradição em Cafuringa por ser uma reminiscência da prática do jongo ${ }^{3}$. Os poemas feitos exaltavam as qualidades da comunidade - a união, a amizade, a brincadeira, a vida no campo, as plantações e os animais - e serão analisados ao longo deste artigo.

Além disso, usamos a fotografia para promover uma reflexão sobre a relação das crianças e dos jovens com o território. Elegemos este recurso porque a fotografia tem a potencialidade de produzir um estranhamento diante da paisagem que eles observam cotidianamente, de desnaturalizar as banalidades e produzir questionamentos. Crianças e jovens caminharam pelos diferentes lugares e tiveram liberdade para fotografar o que mais lhes chamava atenção na observação. No encontro seguinte, apresentamos as fotografias no computador para o grupo todo e fomos selecionando conjuntamente as imagens que deveriam ser reveladas para a montagem da exposição. Esse momento contou com um intenso debate, uma vez que crianças e jovens tiveram que expor suas intenções ao fotografar, interpretar as imagens e chegar a um acordo sobre quais delas deveriam ser selecionadas.

Nesse processo, pudemos entender quais eram suas impressões sobre o território onde vivem e, como gostariam que fossem apresentados para as

3 O jongo é uma forma de expressão que integra dança, canto e percussão de tambores, praticada pelos trabalhadores escravizados de origem Banto, nas lavouras de cana-de-açúcar e de café, no sudeste do Brasil. Foi transmitido pelos mais velhos para as novas gerações, estando presente até hoje em diversas comunidades. O jongo é considerado uma forma de resistência à dominação colonial, pois os negros escravizados dançavam por diversão, como forma de comunicação e de estratégia de sobrevivência. Por isso, os pontos, como são denominados os cantos, possuem um elaborado jogo poético em que a metáfora desempenha um papel importante (PENHA, 2010). Em Cafuringa, essa cultura deixou de ser praticada depois que a matriarca da comunidade faleceu. 
entre cercas, brincadeiras e feitiços: os conflitos e as apropriações do território por crianças e jovens quilombolas

pessoas de fora de Cafuringa. As fotografias revelam uma perspectiva localizada e seletiva dos sujeitos que a produziram, pois sempre há abertura para o registro de novas imagens. Estas, por sua vez, também estão abertas às diferentes interpretações pelos olhares de quem as observa. A fotografia tem sido utilizada em pesquisas em áreas rurais (Gobbi; Finco, 2013; Gusmão; Jobim; Souza, 2008) por permitir ver e conhecer as realidades experimentadas pelas crianças e a provocar narrativas sobre si a partir das imagens.

Essa atividade deu origem às vinte e oito fotografias reunidas na exposição “Cafuringar é muito bom!”, que foi exibida no II Congresso de Estudos da Infância: Politizações e Estesias, realizado em setembro de 2019, na UERJ/Maracanã. Acompanhando a exposição, tem um caderno de recados onde o público manifesta suas impressões e opiniões. De volta ao território, lemos os depoimentos para crianças e jovens, que obtém um retorno do trabalho feito por eles. Assim, buscamos dar visibilidade às crianças e jovens de Cafuringa e reconhecer a fotografia não apenas como um registro do trabalho de campo, mas como um trabalho artístico que tem uma intencionalidade ao ser feito.

Após cada ida a campo, foram produzidos relatórios descritivos de situações e falas que emergiram nas atividades, como registro do que foi observado e realizado, mas também como uma análise dos sentimentos despertados e dos efeitos das ações dos pesquisadores. Optamos no texto por utilizar nomes fictícios dos participantes como uma forma de preservar suas identidades.

Neste artigo, analisamos os relatórios das oficinas, o mapa afetivo, as fotografias e os poemas, a partir de dois eixos temáticos: "Brincadeiras, feitiços e assombrações: as relações de crianças e jovens com o território" e "Entre cercas: os modos de subjetivação de crianças e jovens diante dos conflitos no território", apresentados a seguir.

3 brincadeiras, feitiços e assombrações: as relações de crianças e jovens com o território

Quando crianças e jovens selecionaram as fotografias e os poemas para fazerem parte da exposição, percebemos em suas falas que o propósito das 
imagens e dos textos não era provocar denúncias sobre as dificuldades que vivenciam, embora muitas delas estivessem evidentes, mas apresentar os aspectos positivos da vida em Cafuringa. Eles fotografaram as árvores, as plantações, os animais, as casas onde vivem, a si mesmos caminhando ou fazendo selfs. Utilizaram rimas e improvisações para a construção dos poemas, que expressavam como é viver a infância na comunidade, as brincadeiras, as relações que estabelecem entre si, numa perspectiva de valorização de seu modo de vida.

Ao se referirem à Cafuringa de maneira positiva, afirmam que, apesar da pobreza e da escassez de políticas públicas no território, não há a violência presente nas favelas e periferias das áreas urbanas. Isso faz com que se sintam mais livres para caminhar, brincar nos quintais e na estrada até o anoitecer. Segundo as crianças, o maior perigo que correm na comunidade é de serem picadas por animais peçonhentos, como aranhas e cobras, e de se defrontarem com “assombrações". Numa das oficinas, Tatiana, de treze anos, disse: “Na minha escola, os meus colegas falam que ouvem barulho de tiro, que tem violência, que ouvem aquele barulho... Aqui é um lugar tranquilo, eu nunca ouvi um barulho de tiro, não tem tráfico de drogas, não tem pessoas ruins". É curioso notar que, para elas, a violência está relacionada ao que ocorre nos grandes centros urbanos e que ganha visibilidade através dos meios de comunicação.

A violência rural, mesmo acontecendo frequentemente, permanece não tendo repercussão nos jornais e noticiários. Segundo a Comissão Pastoral da Terra - CPT (2019), estamos vivendo um aumento da violência do campo. Somente em 2018, foram mapeados 1.489 conflitos, que podem ser entendidos como "ações de resistência ou de enfrentamento que acontecem nos diferentes contextos sociais no âmbito rural, envolvendo a luta pela terra, água, direitos e pelos meios de trabalho ou produção" (CPT, 2019, p. 19). Desses conflitos levantados, 1.124 foram por terra em 2018, vividos por camponeses, indígenas, quilombolas e outros povos tradicionais que lutaram para entrar na terra ou para não sair dela e pelos territórios que possuem direito, mas que ainda não foram demarcados. No entanto, as dificuldades e os constrangimentos que crianças e jovens enfrentam parecem não ser reconhecidos como violências devido à invisibilidade que essas questões têm de aparecer na esfera pública. Como Butler 
entre cercas, brincadeiras e feitiços: os conflitos e as apropriações do território por crianças e jovens quilombolas

(2006, p. 23) ressalva “a regulação da esfera da aparência é um modo de estabelecer o que se considerará como realidade e o que não. Também é uma forma de estabelecer que vida pode ficar marcada como vida e que morte contará como morte". Como os conflitos ambientais atingem, principalmente, os povos considerados "sub-humanidade" (Krenak, 2019), as agressões e opressões vividas por eles não são sequer vistas como violência.

As jovens, que revelaram gosto pela escrita de poemas, evidenciaram nas suas produções uma valorização da vida no campo. Cafuringa é apresentada como um lugar tranquilo e que não tem "pessoas ruins".

Ninguém quer morar mais na cidade, mais!

Na roça é mais melhor

Porque tem como dividir!

(Maria, 15 anos)

Podemos observar em no poema, a presença da solidariedade entre os moradores e os laços comunitários, nos versos "na roça é mais melhor, porque tem como dividir". Já a vida urbana, aparece no imaginário das jovens, como sendo marcada pela violência e individualismo, em que as "pessoas querem o bem só para si", sem considerar a coletividade. Para elas, a relação entre campo e cidade se dá de forma antagônica, como uma oposição entre os valores individuais e comunitários.

Os laços com o território vão sendo construídos desde a infância por meio das brincadeiras realizadas coletivamente ao ar livre. As brincadeiras preferidas costumam ter interação entre elas e o ambiente natural, como as de pique, de roda, de corda, de bola, de palmas, de "baleba" (como denominam bolinha de gude), a corrida de cavalinho, o soltar pipa, o subir em árvores, o brincar com a areia. As crianças fazem seus próprios carrinhos e instrumentos musicais com restos de madeira, "rolos" com garrafas pet e fitas de borracha - que quando arrastam no chão produzem estalos -, bonecas e bolsinhas costuradas com retalhos de tecidos, casinhas com caixas de leite, entre outras invenções. Elas aproveitam elementos naturais e materiais que se acumulam no quintal, pois não há coleta de lixo, para produzir artesanalmente seus brinquedos. Nos poemas, as crianças destacam Cafuringa como um lugar para brincar, como percebemos abaixo: 
Cafuringa é muito bom

É bom, é bom demais

Nós vamo brincar

De pique-esconde hoje à noite

E se der vamos brincar mais!

Cafuringa é muito bom

Eu amo brincar demais

Todo mundo gosta de morar aqui

Se quiser pode vir mais!

(Marlene, 12 anos)

Fala meninada

Aqui em Cafu

Eles vêm brincar de bola

Perto de Matutu

(Vicente, 7 anos)

As crianças possuem um laço de amizade entre si e passam a maior parte do tempo brincando juntas. Embora, muitas vezes, tenhamos presenciado disputas em relação ao uso de brinquedos ou dos materiais da pesquisa, percebemos que há uma solidariedade e um cuidado grande entre as crianças. Quando alguma não pode ir ao encontro, as outras sempre se lembram de guardar parte do lanche para entregá-la depois. Aquelas que são mais pobres e não possuem brinquedos são acolhidas pelas outras, segundo Mario, de sete anos, "eu sou muito amigo do Vicente e do Daniel porque eu brinco com os brinquedos deles". A amizade para as crianças tem a ver com estar junto, poder compartilhar os brinquedos e as brincadeiras.

As relações com o território também dizem respeito às interações que as crianças estabelecem com as plantas e os animais. Ao mesmo tempo em que gostam muito dos bichos que têm no quintal, e sempre fazem questão de nos mostrar quando nascem seus filhotes ou quando as galinhas colocam ovo, também têm medo de alguns deles porque "correm atrás" delas ou "podem morder". Assim, elas sabem de quais animais podem ou não se aproximar, ainda que esse aprendizado tenha se dado após ganharem algumas cicatrizes. Histórias 
entre cercas, brincadeiras e feitiços: os conflitos e as apropriações do território por crianças e jovens quilombolas

envolvendo mortes de bichos, machucados e mordidas sempre estavam presentes nas conversas com as crianças pequenas.

Crianças e jovens trabalham na roça, que fica no quintal de casa, alimentam os bichos e têm atividades domésticas para serem feitas. Eles fotografaram como parte do seu cotidiano imagens de: cachorros, galinhas, coelhos, preás, porcos, que cuidam como animais domésticos, e dos pés de jamelão, laranja, seriguela, manga, coqueiro e de uma pequena plantação que possuem no terreno. Esta também apareceu no seguinte poema:

Tudo que precisamos

Plantamos e colhemos

Aqui não é fazenda

Mas é o modo que vivemos

(Maria, 15 anos)

No poema, as crianças revelam que embora Cafuringa não seja uma "fazenda", isto é, um grande terreno voltado para a produção agrícola, os seus moradores sobrevivem do que plantam, se alimentam principalmente de mandioca, abóbora, quiabo, chuchu, maxixe, entre outros. Segundo Laís, de treze anos, "a gente faz escambo, se um tem um boi e o outro tem abóbora, ninguém vai comer só o boi ou só abóbora, a gente troca e todo mundo tem o que precisa" (Relatório de campo, 21/06/2017). Dessa forma, os moradores dividem o que têm para que todos possam sobreviver diante da pobreza a qual estão submetidos. As plantações não são suficientes para que as famílias possam comercializar os produtos, servem principalmente para alimentação de subsistência. A fonte de renda vem do trabalho como empregada doméstica, nas fazendas de cana-de-açúcar e na produção do carvão, atividades marcadas por situações de exploração e desgaste físico. Além disso, as famílias também participam de programas de assistência social, como Bolsa Família, do Governo Federal.

Embora não seja uma "fazenda", as crianças de Cafuringa entram em contato com uma diversidade de animais em seu cotidiano e vão buscando estabelecer semelhanças e diferenças entre eles. Em uma oficina, Helena, de quatro anos discutiu com Rafaela, de seis, se a galinha poderia ou não ser considerada um bicho. Para a mais velha, "galinha não é bicho porque a gente 
mata, joga na panela, frita e come. Bicho é cavalo que corre por aí" (Relatório de campo, dia 28/06/19). A galinha não pode ser considerada "bicho", pois serve para o consumo, se diferenciando de outros animais que possuem liberdade e autonomia, uma vez que sua existência não está sob o controle humano. Além disso, as crianças se lembraram de outros animais: pato, sapo, macaco, coelho do mato, bicho-carpinteiro, besouro, formiga, barata, seriema, lagarta-fogo - que possui esse nome porque "ela faz um fogo que só queima gente" - e lagartixa que "mora no céu porque pula", segundo as crianças.

Nas brincadeiras e conversas, aparecem animais que elas têm medo por serem perigosos, mas que, ao mesmo tempo, exercem algum fascínio, como cobras e pássaros. Vicente define a comunidade assim: "Cafuringa é um lugar cheio de mato para esconder a cobra". As crianças têm medo de serem picadas e contam sobre as diversas espécies, tipos e tamanhos de cobras, que já viram na comunidade. Helena afirmou: "a cobra de madrugada fala comigo, mas me dá medo", e disse também que "só no mato as cobras conversam" (Relatório de campo, dia 28/06/19), assustando todo o grupo que estava com ela.

Existem pássaros que são considerados "assombrados" pelas crianças. Segundo Tatiana, a coruja possui uma "energia ruim e roga praga nos outros". Não se pode olhar dentro dos olhos da coruja, pois a pessoa pode ter a sua vida atravessada "pela morte, por uma maldição ou, então, pelo feitiço, podendo até se apaixonar pela coruja". Tem os pássaros do "mau agouro", cujo canto anuncia que alguém da comunidade vai morrer, e o "Quero-quero", que persegue as pessoas para arrancar os seus olhos. As crianças também acreditam que em Cafuringa vivem o Curupira, o Saci-Pererê e o Lobisomem, personagens tradicionais da cultura popular brasileira.

Outra narrativa aponta a maior jaqueira da comunidade como sendo "enfeitiçada". Ela aparece com destaque na fotografia abaixo (figura 1), selecionada para a exposição, e no centro do mapa afetivo (figura 2). Crianças e jovens nos contaram que "um homem estava andando de moto quando encontrou um cachorro pequeno, ali debaixo da árvore. O cachorro não parou de crescer, foi ficando grande e depois fugiu. Ninguém nunca mais viu o bicho". À noite, dizem que esta mesma jaqueira tomba na estrada, fazendo com que as 
entre cercas, brincadeiras e feitiços: os conflitos e as apropriações do território por crianças e jovens quilombolas

pessoas não consigam mais passar por ali. No entanto, no dia seguinte, a árvore amanhece de pé. As narrativas envolvendo a jaqueira foram transmitidas pelas gerações mais velhas para as crianças e mostraram exercer um papel importante na construção do imaginário da comunidade. A jaqueira possibilita que crianças e jovens se conectem com as memórias de seus antepassados, remetendo a uma relação de ancestralidade com o território.

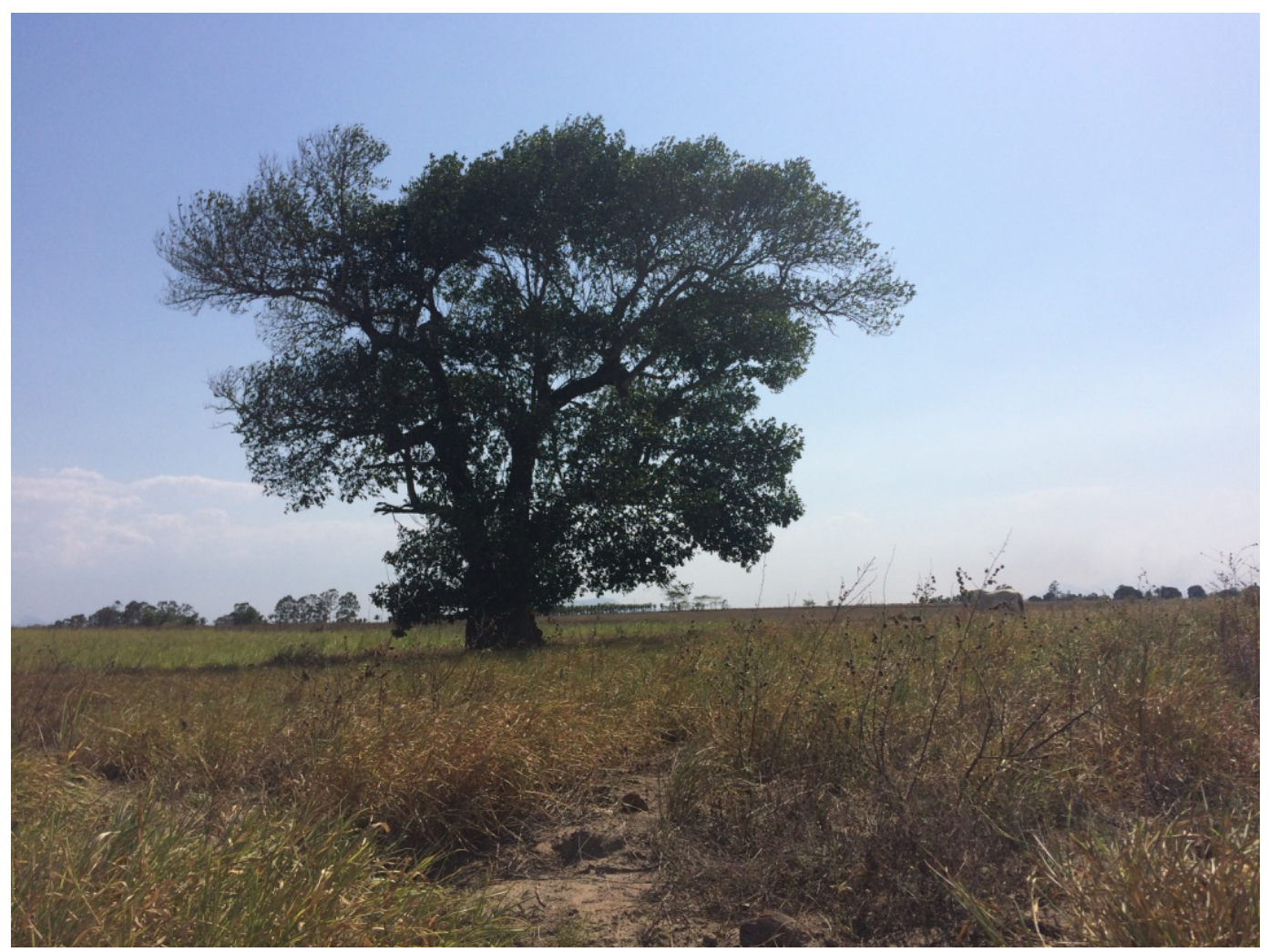

Figura 1: Fotografia da jaqueira "enfeitiçada" tirada pelas crianças

Eliade (2001, p. 17) propõe o termo "hierofania" para exprimir que "algo de sagrado nos revela", que pode se manifestar em qualquer objeto que passa a ter "algo da ordem do diferente". Ao considerar que as árvores e os animais são "enfeitiçados" ou "assombrados", em suas próprias palavras, crianças e jovens demonstram uma relação com a natureza que não é de posse ou dominação como a modernidade construiu. Há algo que escapa do controle e da racionalização instrumental, uma vez que a natureza possui encantamentos e mistérios que não podem ser desvendados. Nos termos do autor, a jaqueira poderia ser compreendida como uma "hierofania", uma manifestação do sagrado para aquela comunidade. Assim, concordamos quando afirma que o "homem moderno experimenta um certo mal estar diante de inúmeras formas de 
manifestação do sagrado: é difícil para ele aceitar que, para certos seres humanos o sagrado pode manifestar-se em pedras ou árvores" (Eliade, 2001, p. 18), como observamos nas narrativas das crianças.

Segundo Descola (2016), a separação entre homem e natureza e a noção de que a natureza é um todo, um conjunto coerente, começou a ganhar corpo na Europa a partir do século XVII, com Descartes, o que permitiu o desenvolvimento da ciência e das técnicas, mas também a sua exploração de forma desenfreada. As plantas, os animais, as terras, as águas passaram a ser vistos somente como recursos naturais, que podem ser estudados cientificamente e rentabilizados a serviço dos homens. "Naquela altura, a natureza havia perdido sua alma e nada mais nos impedia a vê-la unicamente como fonte de riqueza" (Descola, 2016, p. 23). De acordo com o autor, os indígenas na América e em outras comunidades tradicionais, nas diferentes partes do mundo, tratam plantas e animais como pessoas ou sujeitos ao invés de objetos, como observamos no relato da menina que conversava com a cobra. Os não humanos também participam da vida social, com quem estabelecem relações de aliança, hostilidade ou competição.

Dessa forma, percebemos que crianças e jovens de Cafuringa estabelecem uma relação com a terra e a natureza diferente das "fazendas", uma vez que não vêm os animais e as plantas como mercadorias. As relações com a natureza são permeadas de brincadeiras, afetos, "feitiços" e "assombrações", se distanciando das formas eurocêntricas construídas na modernidade. Consideramos essas diferenças presentes nas perspectivas das crianças não como algo "irracional", que deve ser abolido ao longo do seu desenvolvimento para que, ao se tornarem adultas, passarem a ter uma relação mais objetiva e distanciada da natureza. A modernidade e o seu projeto desenvolvimentista geraram a destruição e a colonização dos povos originários que, assim como as crianças, foram vistos como imaturos, dependentes e irracionais. "Quando despersonalizamos o rio, a montanha, quando tiramos deles os seus sentidos, considerando que tudo isso é gratuito e exclusivo dos humanos, nós liberamos esses lugares para se tornarem resíduos da atividade industrial e extrativista" (Krenak, 2019, p. 49). Entender e reconhecer como legítimas outras formas de se relacionar com a natureza e com o território é também zelar pela própria preservação do mundo. 
entre cercas, brincadeiras e feitiços: os conflitos e as apropriações do território por crianças e jovens quilombolas

4 entre cercas: os modos de subjetivação de crianças e jovens diante dos conflitos no território

A produção do mapa afetivo foi uma oportunidade para crianças e jovens refletirem sobre o que consideravam Cafuringa, nomeando seus espaços, o conjunto de casas e terrenos como fazendo parte da mesma comunidade. Ao observarmos os três mapas feitos pelo grupo, notamos alguns aspectos comuns: as casas coloridas, a igreja, a "jaqueira enfeitiçada", a cerca separando a comunidade do haras. Durante a confecção, fizemos perguntas para entender o que elas estavam buscando representar nos desenhos. Mais do que ter uma visão objetiva, o propósito era saber como crianças e jovens se apresentavam para nós, que éramos de fora da comunidade, quais os limites que demarcavam o seu território, o que elas apontavam como sendo pontos importantes, seja para se orientar no espaço, seja pelo papel que possuem na comunidade.

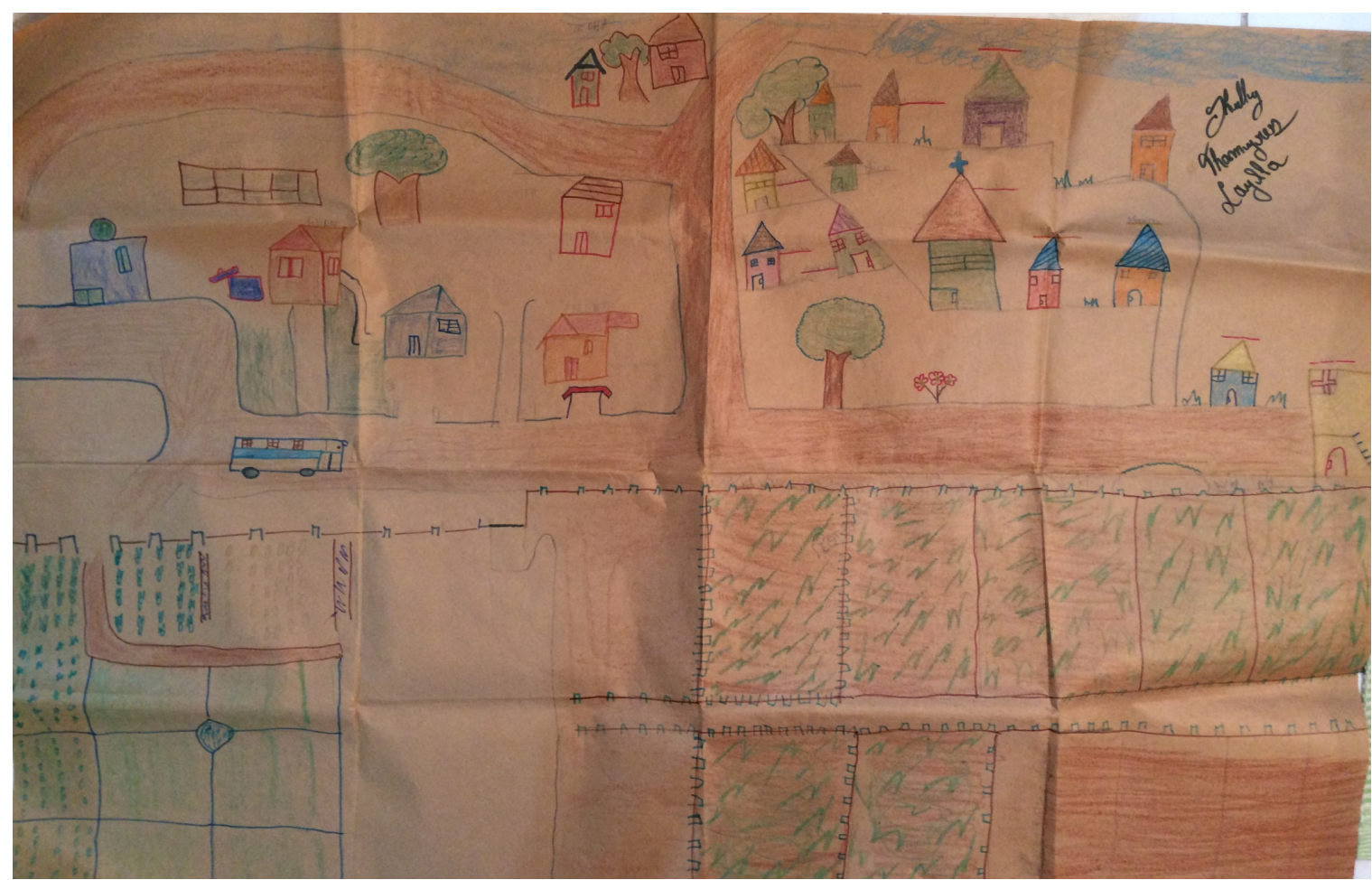

Figura 2: Mapa afetivo feito pelas jovens de Cafuringa 
No mapa feito pelas jovens mulheres (figura 2), chama atenção o espaço que o haras, separado por uma cerca ocupa no cartaz, exatamente a metade. Em outra atividade, as crianças subiram em um carro para fotografar o haras de cima, buscando mostrar a dimensão do seu tamanho. Enquanto desenhavam, escutamos comentários sobre os privilégios dos cavalos em relação às pessoas que vivem do outro lado da cerca. Eles possuem uma área enorme de circulação, "maternidade" e hospital veterinário enquanto os moradores de Cafuringa não contam com serviços públicos em seu território e têm muitas dificuldades para acessar a rede de saúde do município.

Mesmo assim, as jovens fizeram questão de incluir no mapa o haras como parte integrante de Cafuringa, dando destaque para a cerca elétrica que separa as duas realidades. Colocá-lo no mapa significa reafirmar que aquela terra é da comunidade e que foi ocupada de forma violenta. Antes de o haras existir, as famílias faziam plantações naquele terreno, colhiam frutas e usavam um caminho que dava acesso à estrada principal, onde passa o único ônibus que chega próximo à localidade. No entanto, o proprietário quando resolveu instalar o haras colocou a cerca elétrica "de um dia para o outro", segundo as jovens, e impediu os moradores de utilizarem esse caminho, deixando a comunidade isolada. As pessoas passaram a caminhar por uma trilha no meio do pasto para chegar à estrada principal, correndo risco de serem atacadas pelo gado.

Segundo Vicente, “o boi corre atrás da gente, tia, um dia eu e Diego entrou ali e o boi ficou bravo, mas a gente correu igual foguete" (Relatório de campo, dia 25/05/2019). Algumas crianças relataram que deixaram de ir à escola, pois não conseguiram chegar ao ponto de ônibus já que os bois estavam correndo atrás delas. As famílias pediram diversas vezes para o proprietário prender o gado, mas a porteira continua aberta. Além disso, explica Maria: “em dia de chuva, a gente se sente humilhada, sai limpa de casa e chega no ônibus cheia de lama" (Relatório de campo, dia 08/06/2018).

Este terreno onde hoje tem pasto também já pertenceu à comunidade. Ao olhar uma fotografia de uns dez anos atrás, uma Marlene ficou impressionada com as transformações: "Olha essas árvores! Era tudo assim! Hoje diminuiu tudo". Perguntada sobre o porquê de ter diminuído, ela respondeu: "Porque 
entre cercas, brincadeiras e feitiços: os conflitos e as apropriações do território por crianças e jovens quilombolas

construiu mais casas, teve que fazer a estrada e o resto o fazendeiro comprou e acabou com tudo" (Relatório de campo, dia 7/12/2017). Alguns moradores de Cafuringa, diante das dificuldades enfrentadas, foram morar mais próximos ao centro, venderam suas terras para pessoas de fora da comunidade, que passaram a utilizá-las como pasto e para plantação de cana-de-açúcar.

A chegada do haras também limitou o espaço que as crianças têm livre para brincar. Elas falaram muito do incômodo da cerca elétrica, que muitas já se machucaram ao tentarem buscar coisas que caíram do outro lado. Como observamos nessa passagem do diário de campo:

Numa hora, vimos que a bola caiu dentro do haras, um dos meninos queria buscar, e uma das adolescentes disse que não podia, que tinha cerca elétrica e que eles poderiam se machucar. Era uma das únicas bolas que as crianças tinham, e agora não podiam pegá-la por causa da cerca. Essa cena foi bem forte e ficamos pensando como a cerca era perigosa para as crianças. Um dos meninos nos contou que outro dia caiu a mochila dele lá dentro e que o pai teve que ajudá-lo a buscá-la. Ele disse que "de sandália não tem problema, não dá choque. O problema é ir descalço ou encostar o corpo, tem que tomar muito cuidado" (Relatório de campo, dia 29/09/2017).

Quando as crianças foram perguntadas sobre quais lugares elas gostariam de ir e que não eram permitidas, todas apontaram o haras. Diego, de seis anos, contou que seu irmão já tinha ido e falado "que lá dentro era muito lindo, tinha um monte de pássaro e até um lago" (Relatório de campo, dia 16/10/2017). Foi curioso ele falar que havia um lago, considerando que a falta de água é um dos principais problemas de Cafuringa e, em período de muita seca, os moradores precisam até buscar água numa localidade próxima. Notamos também um encantamento pelos cavalos do haras, que são muito valiosos e bonitos. De acordo com uma jovem, o haras até já apareceu na televisão, pois produz cavalos de corrida e de exportação para outros países, como os Estados Unidos. Dessa forma, no imaginário, o haras aparece como um local de riquezas, das quais os moradores de Cafuringa são impedidos de usufruir, um contraste com a realidade da comunidade marcada pela pobreza e precariedade de infraestrutura.

Ao mesmo tempo em que crianças e jovens têm raiva do haras, pelas dificuldades que impõe à vida no território, também ficam fascinados pelos 
animais que circulam pelo local. Podemos relacionar essa situação com que Fanon (2005) afirma em relação ao arranjo colonial, em que o mundo do colono é um mundo hostil, que rejeita, mas ao mesmo tempo é um mundo que dá inveja para os colonizados: “Esse mundo hostil, pesado, agressivo porque rejeita com todas suas asperezas a massa colonizada, representa não o inferno do qual se desejaria afastar-se o mais rapidamente possível, mas um paraíso ao alcance da mão, protegido por terríveis cães de guarda" (Fanon, 2005, p. 69).

Diante da impossibilidade de ter acesso ao "paraíso", as crianças pequenas têm como uma de suas brincadeiras favoritas a corrida de cavalinho, brinquedo produzido por elas com um cabo de vassoura e uma cabeça de plástico. Como Brougère (2010, p. 111) coloca a criança "brinca com as condições materiais e imateriais que lhes são propostas". Nesse caso, a brincadeira tão comum no universo infantil, ganha um novo sentido quando é feita pelas crianças que vivem numa situação de conflito ambiental (Acselrad, 2004). Podemos compreender como uma forma imaginária delas atravessarem a cerca elétrica para interagirem com os cavalos do haras que apenas podem avistar de longe. De acordo com Borba (2009), a brincadeira não é uma cópia da realidade, mas se define como um espaço onde a realidade pode ser pensada, refletida, discutida, transformada e reinventada. Assim, pela brincadeira, as crianças reinventam a situação de opressão em que vivem. Podem correr com seus próprios cavalos, disputar corridas com seus colegas, percorrer campos extensos, experimentar em seu próprio tempo a criação de um novo ambiente, uma vez que a realidade presente sempre se mostra restrita e limitada. Os cavalos também estiveram presentes nas fotografias tiradas por um menino - mas neste caso foram os cavalos de vizinhos - talvez no sentido de mostrar que Cafuringa também possui essa riqueza, como vemos na imagem abaixo: 
entre cercas, brincadeiras e feitiços: os conflitos e as apropriações do território por crianças e jovens quilombolas

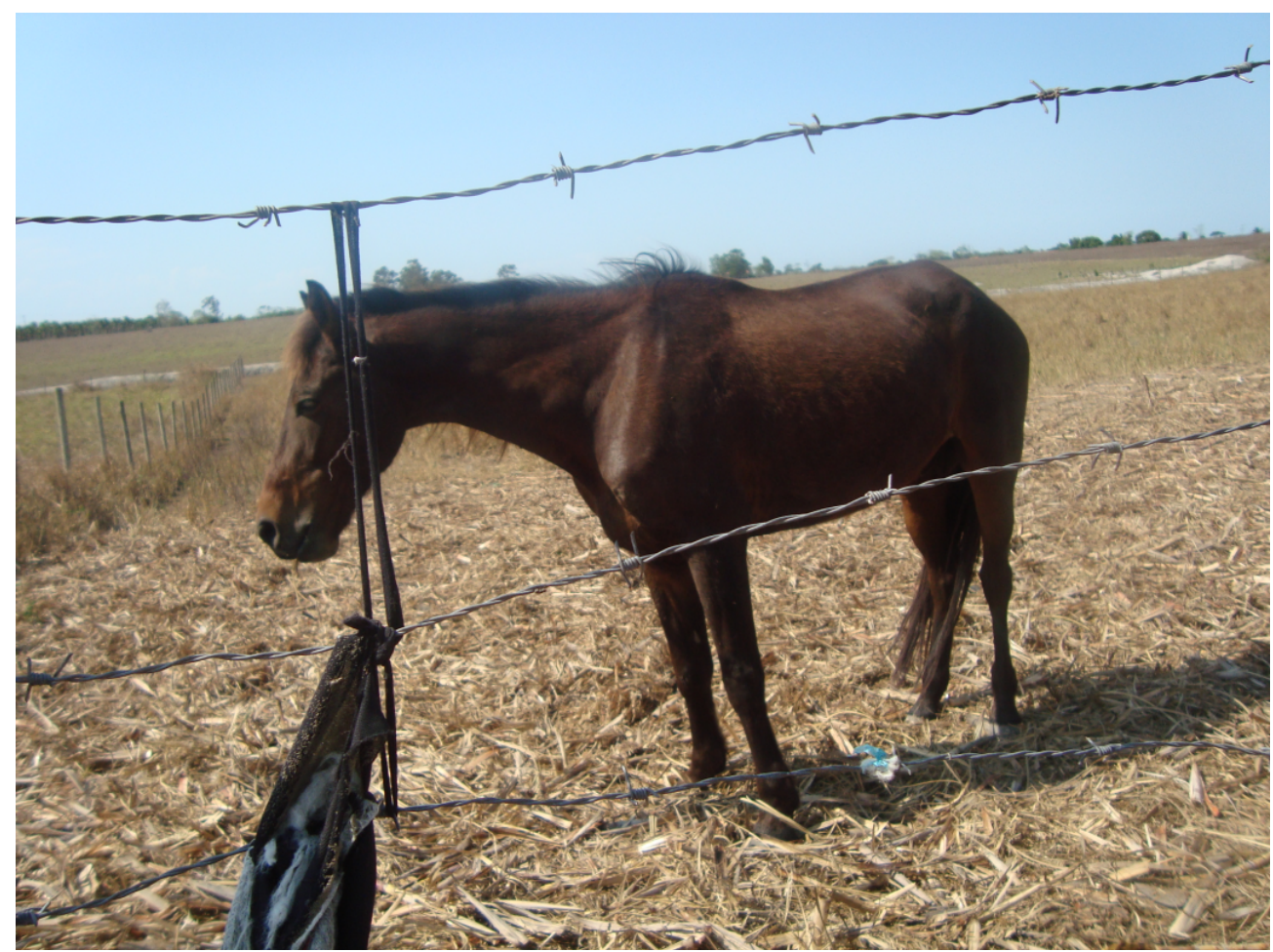

Figura 3: Fotografia de um cavalo feita por um menino

Esse "mundo hostil" do colono também gera estranheza numa criança pequena, de três anos, quando questiona para quê servem as cercas e porque um terreno tão grande está cercado, impedindo as outras pessoas de usarem, como observamos na passagem abaixo:

Manoel perguntou "por que existe essa cerca?", apontando para a cerca elétrica que divide o haras de Cafuringa. Elisa ficou sem saber a princípio o que responder e acabou explicando: "o dono do haras colocou a cerca para dizer que aquela terra tem um dono". Manoel, então, olhou pra tudo que tinha dentro do cercado do haras e questionou "então aquela árvore é dele também?". Elisa disse que sim. Depois disso, ele começou a apontar para os bois e para todas as coisas que via e a perguntar se eram do dono do haras (Relatório do campo, dia 26/10/2018).

Manoel tenta com suas questões elaborar como indivíduos podem ser donos da terra, das árvores e dos animais e, aos poucos, construir a noção de propriedade privada e de subordinação da natureza à dominação dos homens. $\mathrm{O}$ olhar de estranhamento da criança, como aquela recém-chegada ao mundo (Arendt, 2005; Castro, 2013), revela o seu lugar geracional, uma vez que ainda precisa se apropriar das regras e normas existentes - elaboradas e criadas pelos adultos - ao mesmo tempo em que evidencia a arbitrariedade delas e problematiza a razão da existência das coisas tal como elas são. A condição 
humana da natalidade se dá a cada novo nascimento, pois os recém-chegados vêm ao mundo na qualidade de estranhos e possuem "a capacidade de iniciar algo novo, isto é, de agir" (Arendt, 2005, p. 17). Segundo Castro (2013, p. 30), "como recém-chegadas, as crianças precisam que alguém lhes diga como o mundo funciona" já que tudo é novo para elas. A experiência da primeira vez se refere ao assombro permanente perante o que vai vir, quando se está de frente ao desconhecido, sem que haja o dito para servir como guia para lidar com a realidade. Nessa fala de Manoel, percebemos o seu assombro diante da cerca e de uma quantidade imensa de terras e animais que não podem ser acessados pela comunidade. Ele pede a ajuda para que alguém, com mais experiência de vida, possa explicar aquilo que foge do seu entendimento.

Como Cafuringa é pequena e todos têm algum laço de parentesco, há um uso mais compartilhado dos espaços. As crianças podem caminhar pelos terrenos, subir em árvores, correr atrás dos pássaros, cachorros, gatos e galinhas. Embora algumas casas tenham cercas vivas, no mapa feito por elas (Figura 2), não há nada que delimite os terrenos de cada moradia, o que representa a livre circulação na comunidade e a convivência com os vizinhos. Quando chamamos as crianças para realizar os encontros, nunca sabemos em qual casa elas estão, pois é comum estarem brincando conjuntamente pelos quintais. Essa liberdade de circulação entre as casas entra em choque com a cerca elétrica do haras, que informa claramente que as pessoas da comunidade não são bem-vindas ali, reforçando a intolerância e a discriminação.

As jovens explicaram que a comunidade não possui água encanada porque o proprietário do haras impediu a passagem do encanamento pela sua propriedade, o que gerou um clima de revolta em todos no grupo. A água que abastece as casas vem de poços simples ou também conhecidos como caipiras, construídos pelos moradores que puxam manualmente a água que vão precisar e armazenam em baldes e latões. Além do trabalho de pegar a água, há o risco de contaminação já que a comunidade não tem saneamento básico.

Elas também comentaram do veneno que os funcionários do haras lançam, nas palavras de Tatiana: "eles tacam veneno em volta da cerca e sobe uma fumaceira amarga e fedida". Maria concluiu: "tudo de ruim tá do lado de lá" 
entre cercas, brincadeiras e feitiços: os conflitos e as apropriações do território por crianças e jovens quilombolas

(Relatório de campo, dia 25/05/2019). Geralmente, o veneno é colocado na cerca para impedir o crescimento de plantas e árvores que demandariam um trabalho para capinar. Como há uma distância pequena da cerca para as casas, as pessoas inalam o veneno que pode gerar diversas doenças e complicações de saúde.

Esses casos apontados pelas jovens evidenciam como o racismo, criado e utilizado para justificar o processo de colonização, perdura até hoje. Para Mbembe (2018), a ocupação colonial inscreveu no terreno um novo conjunto de relações sociais e espaciais, o que significou relegar o colonizado a uma terceira zona, entre o estatuto de sujeito e objeto. O racismo produz a separação entre vidas humanas tomadas como superiores e inferiores, entre os grupos que merecem viver e aqueles que podem se expor ao risco e morrer. Ao desumanizar os povos, possibilita a naturalização da violência e a "aceitabilidade do fazer morrer" (Mbembe, 2018, p. 18). A sociedade se mobiliza e sente diferentemente as perdas, pois enquanto algumas são altamente divulgadas e despertam a comoção, outras nem se tornam públicas. Como afirma Butler (2006, p. 17), “a distribuição diferencial da dor decide que classe de sujeito merece um luto e que classe de sujeito não, produz e mantém certas concepções excludentes de quem é normativamente humano".

Assim, criar condições de vida cada vez piores para tornar insustentável a presença da comunidade no local é uma das estratégias que latifundiários e empresários utilizam para poder ampliar suas terras. Percebemos, portanto, que a cerca elétrica demarca mais do que o espaço ocupado pelo haras, simboliza o racismo, a desigualdade social e as diferenças dos modos de viver presentes nos dois territórios. O conflito ambiental se dá porque existe uma relação de disputa entre duas lógicas distintas que operam em Cafuringa. O site do haras afirma que a empresa tem como objetivo "produzir animais de ponta para atender o mercado, com foco nas provas de velocidade", unindo a "paixão aos negócios" de seu dono. Nesse sentido, a preocupação principal da empresa é com a criação de animais e a expansão dos seus rendimentos, nem que para isso seja necessário prejudicar aqueles que estão ao seu redor. A terra como um "negócio" contrasta com a terra enquanto espaço vivido por crianças e jovens, que é afetivo, 
produzido nas interações e parte da natureza, lugar de brincadeira, encontro, memória e identidade para seus moradores.

\section{5 considerações finais}

O Brasil passou por um longo processo de colonização que ainda deixa marcas violentas nas formas de se relacionar com as comunidades quilombolas, produzindo desigualdades sociais, discriminações raciais e a desvalorização de suas culturas e conhecimentos. Garantir a posse de terra é o primeiro passo para preservar a existência dos povos tradicionais e de seus modos de vida, que durante muito tempo foram considerados bárbaros, atrasados, incivilizados, primitivos; nomeações estas que justificaram o processo de colonização. Assim como negros e indígenas, as crianças foram consideradas mais próximas à natureza, uma "sub-humanidade" (Krenak, 2019), devendo passar pelos processos de desenvolvimento e socialização para alcançar à racionalidade adulta.

Neste artigo, investigamos as relações que crianças e jovens quilombolas estabelecem com o território, seus usos e apropriações, e como lidam diante dos conflitos vivenciados na comunidade. Notamos que através das brincadeiras realizadas ao ar livre exploram os espaços da comunidade, interagem com a terra, bichos, plantas e árvores. Estes, para crianças e jovens, podem ser "enfeitiçados", "assombrados", guardam algo de sagrado, ao mesmo tempo em que fascinam também geram medo. $\mathrm{O}$ território guarda memórias que remetem aos seus ancestrais, que foram transmitidas de geração em geração.

Os conflitos com o haras revelam a diferença entre a perspectiva capitalista construída na modernidade, que transforma a natureza em mercadoria, a terra em "fazenda", em oposição às formas de crianças e jovens quilombolas se relacionarem com as plantas e os bichos, muitas vezes, como sujeitos. Em suas narrativas, deixam claro que, de um lado, tem o haras cujos animais são tratados como se suas vidas valessem mais do que a das pessoas que vivem do outro lado da cerca, a ponto de negarem o acesso à água encanada, contaminarem o ar e o solo com veneno, submeterem às crianças ao risco de se machucarem ao tomarem choque elétrico na cerca. Do outro lado, há o pasto onde o gado circula 
entre cercas, brincadeiras e feitiços: os conflitos e as apropriações do território por crianças e jovens quilombolas

livremente, gerando medo nas crianças de serem atacadas, restringindo sua circulação e fazendo até com que faltem à escola por não conseguirem chegar ao ponto do ônibus. Assim, Márcia, de dezenove anos, fez uma síntese esclarecedora sobre a sua realidade: "a gente vive num corredor cercado entre o boi e o cavalo" (Relatório de campo, dia 27/05/2019).

O "assombro" (Castro, 2013) da criança diante da cerca elétrica, buscando entender os motivos de sua existência e dessa realidade que a desumaniza, que considera a existência de vidas que valem mais do que outras, nos faz lembrar que a realidade é uma construção social e, portanto, passível de transformações. Seus estranhamentos diante de um mundo de desigualdades sociais e discriminações raciais, que cria cercas e fronteiras, nos faz questionar sobre o projeto de civilização construído e mantido por nós, adultos. Dar visibilidade às vozes de crianças e jovens quilombolas permite problematizar a propriedade privada da terra, o capitalismo que transforma tudo em mercadoria, e vislumbrar outras formas de relação com a natureza, o território e as pessoas.

\section{referências}

Acselrad, Henri. Conflitos Ambientais no Brasil. Rio de Janeiro: Relume Dumará, 2004.

Alanen, Leena. Estudos feministas/estudos da infância: paralelos, ligações e perspectivas. In: Castro, L. R (org). Crianças e jovens na construção da cultura. Rio de Janeiro: NAU, 2001, p. 69-92.

Arendt, Hannah. A condição humana. Rio de Janeiro: Forense Universitária, 2005.

Arruti, João Maurício. Introdução: territórios negros In: Arruti, J. M. (Org) Territórios negros do Rio de Janeiro: história, antropologia e alternativas jurídicas. Rio de Janeiro: UERJ, 2002, p. 4-13.

Borba, Angela Meyer. A participação social das crianças nos grupos de brincadeira: Elementos para a compreensão das culturas da infância. Revista Educação em Foco, v.13, n. 2, p. 139-156, 2009.

Brasil. Decreto $n^{\circ}$ 4887, de 20 de novembro de 2003. Diário Oficial da União, Brasília, DF, 21 nov. 2003. Disponível em: http://www.planalto.gov.br/ccivil_03/decreto/2003/D4887.htm.

Acesso em: 15 jan. 2020.

Brougère, Gilles. Brinquedo e Cultura. São Paulo: Cortex. 2010

Burman, Erica. Deconstructing Developmental Psychology. Londres: Routledge, 2008.

Butler, Judith. Vida Precaria: el poder del duelo y la violencia. Buenos Aires: Paidós, 2006. 
Castro, Lucia Rabello de. Da invisibilidade à ação, crianças e jovens na construção da cultura. In: Castro, L. R. (Org.), Crianças e jovens na construção da cultura. Rio de Janeiro: Nau, 2001, p.19-46.

Castro, Lucia Rabello de. O futuro da infância e outros escritos. Rio de Janeiro: 7Letras, 2013.

Cohn, Clarice. Concepções de infância e infâncias. Um estado da arte da antropologia da criança no Brasil, Civitas, v.13, n. 2, p. 221-244, 2013.

Comissão Pastoral da Terra - CPT. Conflitos no Campo Brasil 2018. Goiânia: CPT, 2019.

Descola, Philipe. Outras naturezas, outras culturas. São Paulo: Editora 34. 2016.

Eliade, Mircea. O sagrado e o profano: a essência das religiões. São Paulo: Martins Fontes, 2001.

Fanon, Franz. Peles negras, máscaras brancas. Salvador: EDUFBA, 2008.

Fanon, Franz. Os condenados da Terra. Minas Gerais: Editora UFJF, 2005.

Gobbi, Márcia; FINCO, Daniela. Meninas e meninos em assentamento do MST: representações e diferentes modos de ver e sentir da infância do campo. In: Silva, I. O. ; Silva, A. P. S.; Martins, A. A. (Org.). Infâncias do Campo. Belo Horizonte: Autêntica, 2013, p. 59-76.

Favret-Saada, Jeanne. Ser afetado. Cadernos de Campo, 13, p.155-161, 2005.

Gusmão, Denise \& JOBIM E SOUZA, Solange. A estética da delicadeza nas roças de minas: sobre a memória e a fotografia como estratégia de pesquisaintervenção. Psicologia E Sociedade, v. 20, p. 24-31, 2008.

Krenak, Ailton. Ideias para adiar o fim do mundo. São Paulo: Companhia das letras, 2019.

Mbembe, Achile. Necropolítica: biopoder, soberania, estado de exceção, política de morte. São Paulo: n-1edições, 2018.

Penha, Geneci Maria da. A voz do tambor: a Noinha e o jongo. Campos dos Goytacazes, 2010.

Qvortrup, Jeans. Nove teses sobre a infância como um fenômeno social. Proposições, v. 22, n. 1, p.199-211, 2011

Santos, Milton. Por uma outra globalização: do pensamento único à consciência universal, São Paulo: Editora Record, 2008.

recebido em: 09.02.2020

aprovado em: 16.08 .2020 